\title{
Sources of uncertainty for the Determination of Chlorpyrifos by Gas Chromatography Equipped with Flame Photometric Detector
}

\author{
O. A. Zalat*, M. A. Elsayed, M. S. Fayed, M. K. Abd El Megid \\ Egyptian Armed Force, Cairo, Egypt \\ *E-mail address: zalat44@yahoo.com
}

\begin{abstract}
Analysts are increasingly being required to evaluate the uncertainty associated with methods. Estimating the uncertainty of an analytical result is an essential part of quantitative analysis. This paper discusses the sources of uncertainty of chlorpyrifos determination by gas chromatography equipped with flame photometric detector (GC-FPD). The analysis was performed on HP-5 MS, $30 \mathrm{~m}$ x $0.32 \mathrm{~mm}$ capillary column with a $0.25 \mu \mathrm{m}$ stationary film thickness using ultra pure nitrogen $(99.9999 \%)$ as a carrier gas at 25 psi constant pressure. The method has been optimized. Factors affecting quantization of chlorpyrifos such as injector temperature, carrier gas inlet pressure, air to hydrogen ratios and initial temperature program have been studied to get the best sensitivity, minimum delectability. The liner range of the detector was from $0.15 \mathrm{ng} / \mathrm{ml}$ to $1200 \mathrm{ppm}$, the minimum detection limit was $0.15 \mathrm{ng} / \mathrm{ml}$ and the relative standard deviation was 0.839 .
\end{abstract}

Keywords: Sensitivity; Minimum detectability; Chlorpyrifos; Injection

\section{INTRODUCTION}

Chlorpyrifos is an organophosphorous insecticide widely used for pest control in agriculture and with minimum degree for indoor applications. The structure of chlorpyrifos is shown in Figure 1.

Wide range of harmful effects of the organophosphates on humans are observed [1]. The immediate effect of an acute exposure is the accumulation of acetylcholine at the receptors, giving rise to the characteristic symptomatology of the acute organophosphorous poisoning [2].

Chlorpyrifos is stable in air (nonvolatile) and it is not sensitive to ultra violet radiation. It is stable to neutral and weakly acidic solution, but it is hydrolyzed by strong bases. The rate of chlorpyrifos hydrolysis increases with both $\mathrm{pH}$ and temperature, its structure is shown in Figure $1[2]$. 


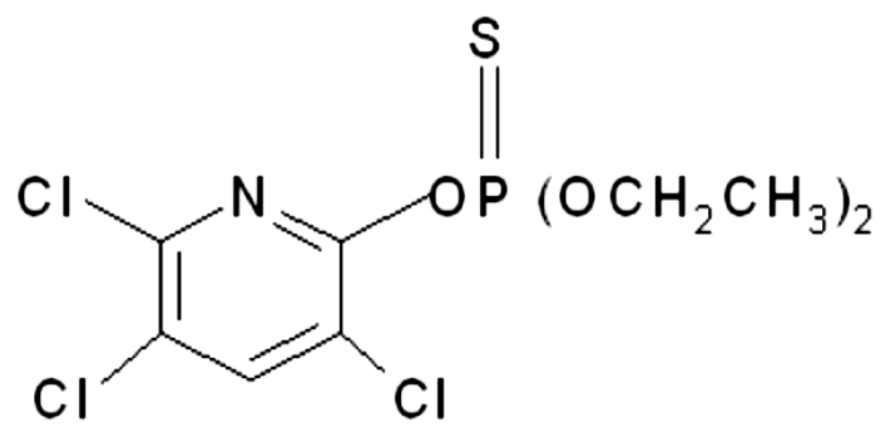

Figure 1. Chlorpyrifos structural formula.

Chlorpyrifos lethal dose in rats is (LD50) $202 \mathrm{mg} / \mathrm{kg}$. Safety measures for farm workers are very poor. Many of them do not strictly follow the manufacturer's directions for use of the commercial formulations containing $48 \%(\mathrm{w} / \mathrm{v})$ of chlorpyrifos marketed which strongly recommend that it is not to be applied by cold fogging or atomizing [2]. Chlorpyrifos analysis is carried out conventionally by gas chromatography (GC) or by high-performance liquid chromatography (HPLC) [3-8]. Flame photometric detector detects compounds by burning it in a flame and sensing the increase of light emission from the flame during that combustion process [9]. Therefore, the FPD is a flame optical emission detector comprised of a hydrogenair flame, an optical window for viewing emissions generated in the flame, an optical filter for spectrally selecting the wavelengths of light detected [9]. The aim of this search is to optimize and discuss the factors affecting detector response to get the best determination results of chlorpyrifos with gas chromatography technique equipped with FPD.

\section{EXPERIMENTAL}

\section{1. Materials and method}

Chlorpyrifos was purchased from sigma Aldrich; purity $>97 \%$. Stock standard solutions were prepared by weighing about $1 \mathrm{mg}$ of pure material. Chlorpyrifos was dissolved in chloroform and diluted to a volume $25 \mathrm{~mL}$. The solutions were then transferred into TFEfluorocarbon-sealed screw-cap vials, stored at $4{ }^{\circ} \mathrm{C}$ and protected from light. A set of test samples were Prepared by dilution from stock standard solutions to cover a wide range of concentrations $(0.0015-1200 \mathrm{ppm})$ of the test substance.

\section{2. Instrumentation}

Agilent, 7890A gas chromatograph, Auto sampler (7693-series) with a split/ splitless injector system and a flame photometric detection with sulphur filter were used. Ultra pure nitrogen $(99.9999 \%)$ at 25 psi constant pressure after passing through a molecular sieve trap was used as carrier gas. The injection port was held at $250{ }^{\circ} \mathrm{C}$ and used in the splitless mode. Separation was carried out on a HB-5, $30 \mathrm{~m} \times 0.32 \mathrm{~mm}$ capillary column with a $0.25 \mu \mathrm{m}$ stationary film thickness (Agilent Technologies). Operating conditions were as follows: detector temperature, $250{ }^{\circ} \mathrm{C}$ and hydrogen was used as detector at a flow of $150 \mathrm{~mL} / \mathrm{min}$. The flow of zero air $(99.999 \%$ ) for FPD was $110 \mathrm{~mL} / \mathrm{min}$. The column temperature was maintained at $60{ }^{\circ} \mathrm{C}$ for $1 \mathrm{~min}$ and then programmed at $10{ }^{\circ} \mathrm{C} / \mathrm{min}$ to $250{ }^{\circ} \mathrm{C}$, and held for 1 
min. The total analysis time was $11 \mathrm{~min}$. The volume of sample injected in splitless mode was $1.00 \mu \mathrm{L}$.

\subsection{Analytical procedure}

Injector temperature was studied in the range from 150 to $250{ }^{\circ} \mathrm{C}$ while fixing the detector temperature at $250{ }^{\circ} \mathrm{C}$. The used temperature program was set at an initial temperature at $60{ }^{\circ} \mathrm{C}$ (hold $1 \mathrm{~min}$ ), final temperature at $250^{\circ} \mathrm{C}$ (rate $20^{\circ} \mathrm{C} / \mathrm{min}$, hold $7 \mathrm{~min}$ ).

The detector response for was then measured by injecting $1 \mu 1$ of 4 ppm of chlorpyrifos. By using the same standard solution prepared above the initial temperature program was varied in the range of $50-100{ }^{\circ} \mathrm{C}$ while fixing other conditions. The change in retention time and detector response was then measured against initial temperature. The FPD response was also studied with the change in carrier gas flow inlet pressure (Nitrogen in this case) from 10 to $35 \mathrm{psi}$. The detector response was then measured and tabulated. The effect of changing the air to hydrogen ratio supplied to the detector from 0.2 to 1.2 volumetric ratio was also studied .

\section{RESULTS AND DISCUSSION}

\section{1. Injector temperature}

Injector temperature was studied in the range of $120-250{ }^{\circ} \mathrm{C}$ while fixing the detector temperature at $250{ }^{\circ} \mathrm{C}$ and using suitable temperature program. Initial temperature was set at $60{ }^{\circ} \mathrm{C}$ (hold $1 \mathrm{~min}$ ), final temperature at $250{ }^{\circ} \mathrm{C}$ with increasing rate $20{ }^{\circ} \mathrm{C} / \mathrm{min}$, hold $7 \mathrm{~min}$ ). Figure 2 shows the relation between injector temperature and detector response (peak area). The figure summarized that the highest peak area of all samples were obtained at $250{ }^{\circ} \mathrm{C}$, this could be attributed to the highest volatility of the samples introduced in the column.

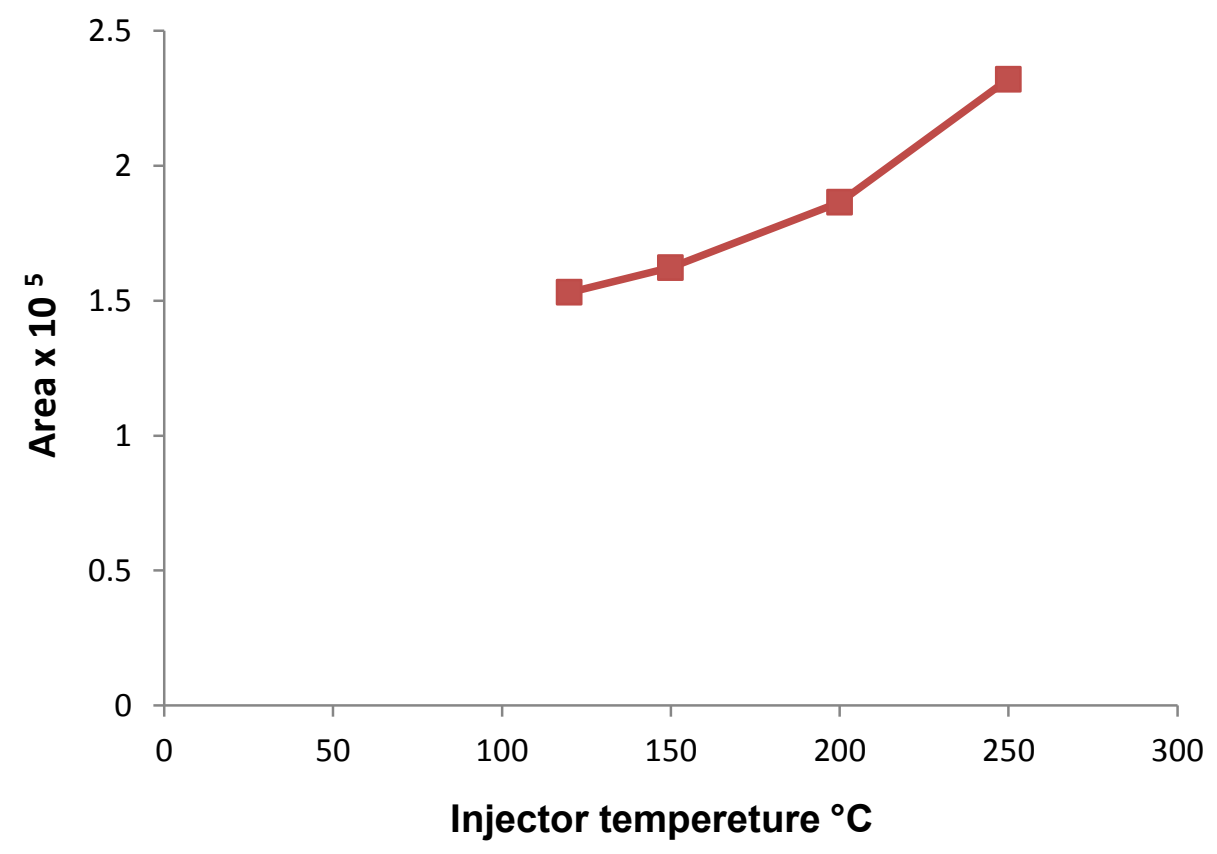

Figure 2. Effect of injector temperature on peak area using splitless mode injection volume $(1 \mu 1)$ detector temperature $250{ }^{\circ} \mathrm{C}$. 


\section{2. Temperature programming}

For the purpose of this optimization the initial temperature was varied in the range of 50 $-100{ }^{\circ} \mathrm{C}$ while fixing the injector temperature $250{ }^{\circ} \mathrm{C}$ and the detector temperature at $250{ }^{\circ} \mathrm{C}$. The results show that as the initial temperature increases the retention time of analytes decreases. Figure 3(a) Shows the relation between initial temperature program and retention time. From the figure it was clear that as the initial temperature increases the retention time decrease this was due to fast elution of the analyte from the column. This parameter is very important in optimizing peak resolution. Figure 3(b) Showed the relation between initial temperature program and detector response (peak area). At temperature between 50 to $70{ }^{\circ} \mathrm{C}$ the detector response (peak area) increase this may due to shape of the produced peak area shape in which at low temperature the peak was broad which gives more area count however at more higher temperature above $70{ }^{\circ} \mathrm{C}$ the peak shape was observed to be sharp, that produced lower area count. Therefore, the optimum initial temperature was found at $70{ }^{\circ} \mathrm{C}$ which was selected because of short retention time and high peak area
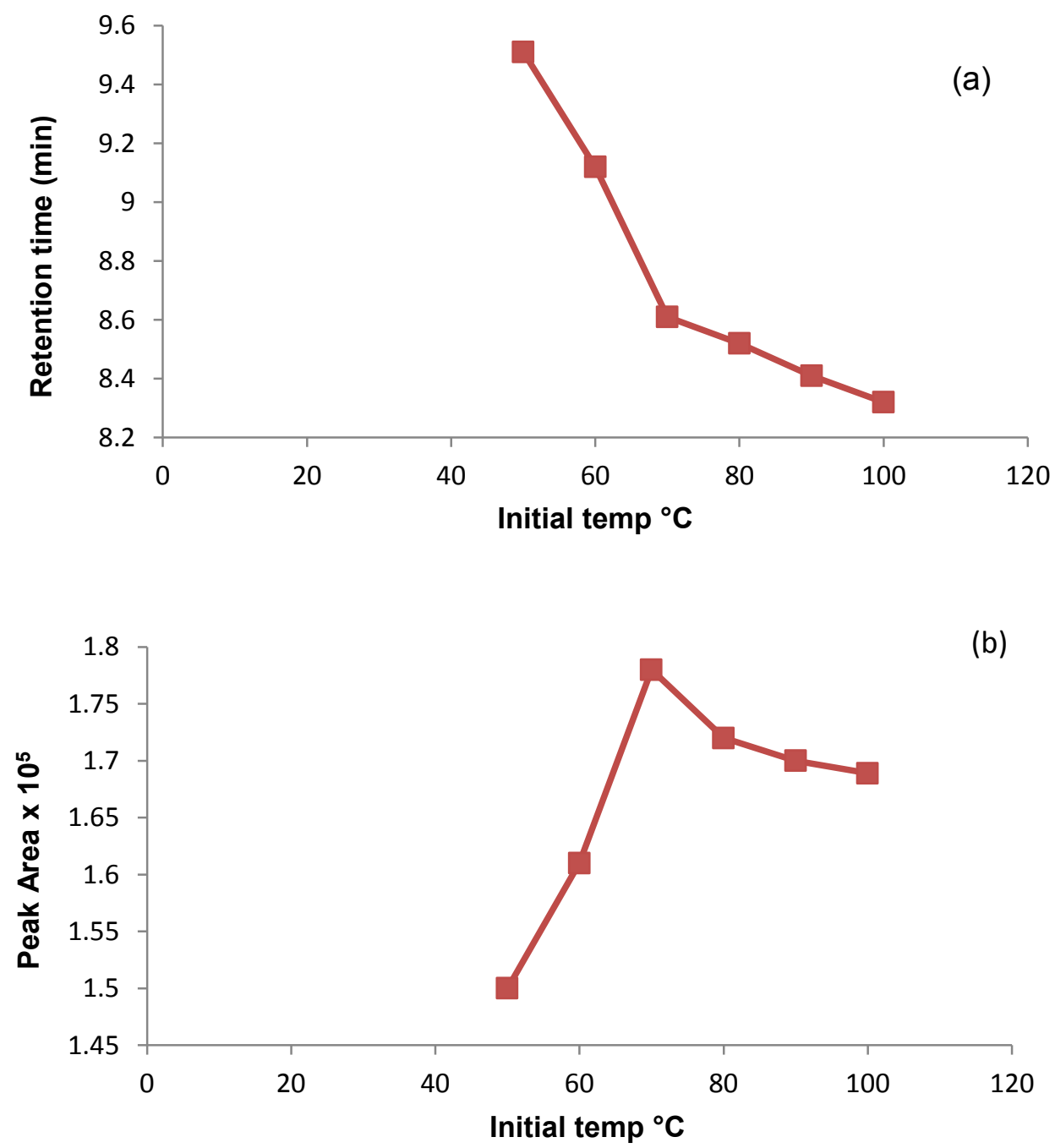

Figure 3. Effect of initial temperature program on (a) retention time and (b) peak area using splitless mode injection volume $(1 \mu \mathrm{l})$ detector temperature $250{ }^{\circ} \mathrm{C}$. 


\section{3. Carrier gas inlet pressure}

The FPD response was also found to be dependent on the carrier gas inlet pressure (nitrogen in this case). Figure 4 showed the relation between the detector response and the carrier gas pressure, it was cleared that the FPD signal increases with increasing carrier gas flow-rates; this was to a certain value ( $25 \mathrm{psi})$ this may owing to the enhancing for a decrease in the flame temperature to be (cooled flame) in which at this region the emission from the species (HPO and $\mathrm{S}_{2}$ ) is favoured. Above this cetain value (25 psi) a decrease in the detector response was observed. It may due to highly lowering in the flame temperature. The suitable pressure was as in standard method at 25 psi. Carrier gases must be especially purified for use in the flame photometric detector because not highly purified led to substantial narrowing of the linear dynamic range of the detector.

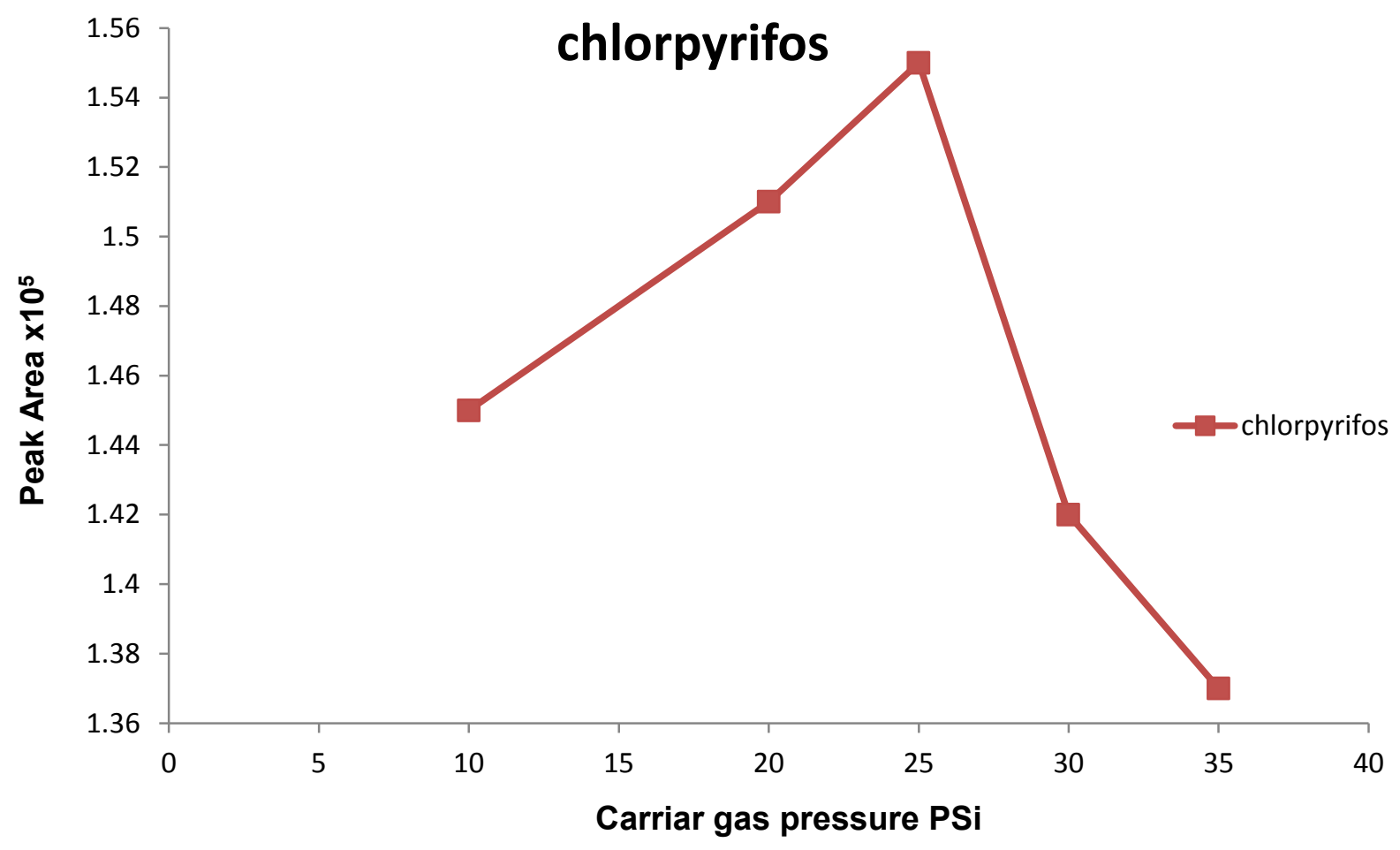

Figure 4. Effect of carrier gas inlet pressure splitless mode injection volume $(1 \mu 1)$ detector temperature $250^{\circ} \mathrm{C}$.

\section{4. Effect of Air to hydrogen ratio supplied to the detector}

The effect of changing the ratios of air-to-hydrogen from 0.2-to-1.2 in detector response has been studied. Detector response was measured using different ratios and the results are shown in Figure 5. 


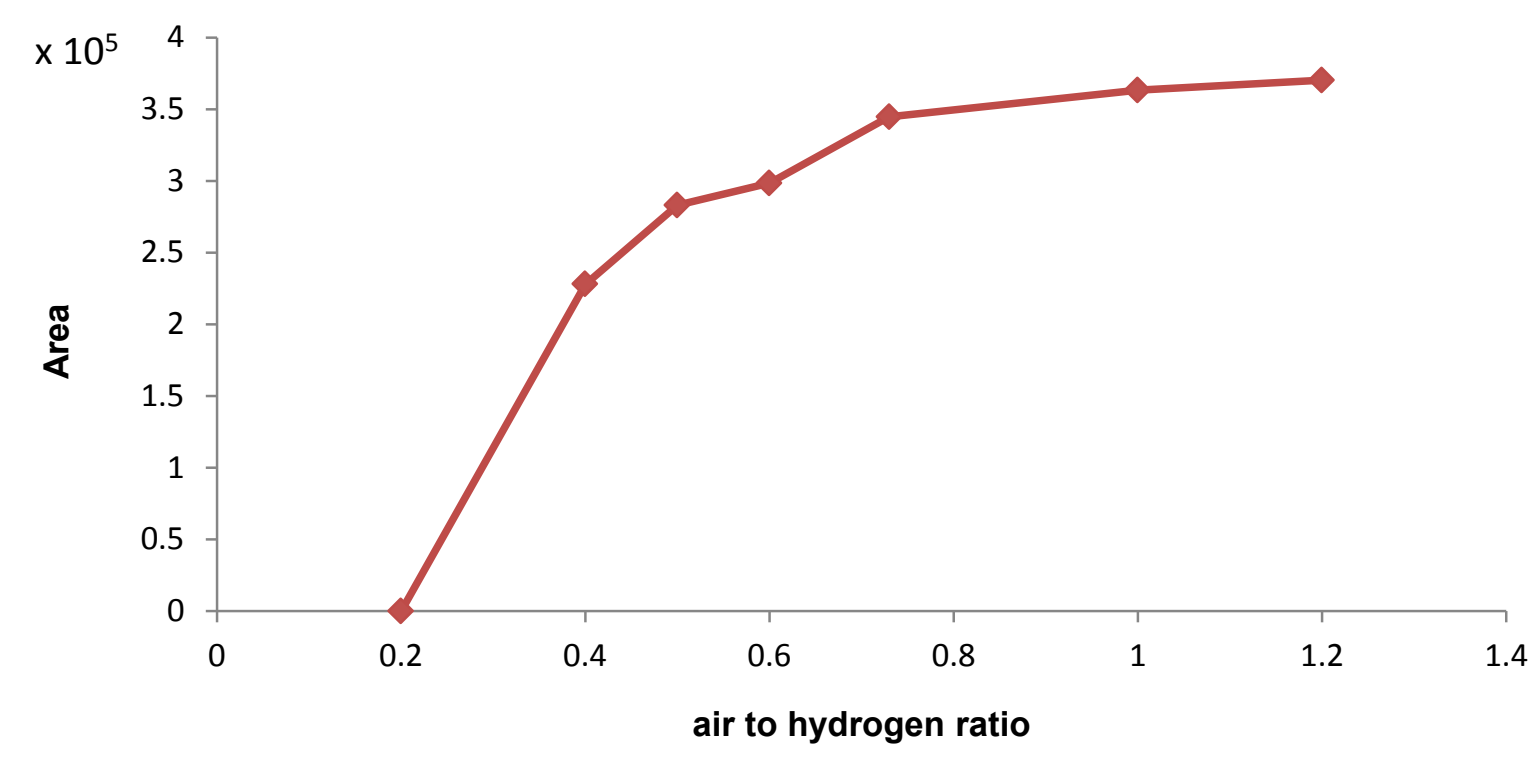

Figure 5. Detector responses at different air-to-hydrogen ratios (volumetric ratio), P-mode, splitless mode, injection volume $(1 \mu \mathrm{l})$ and detector temperature $250{ }^{\circ} \mathrm{C}$.

As shown in Figure 5, for ratios at 0.2 and below, the amount of oxygen present in the gas mixture is not enough for the ignition of the flame and the devise give signal flame out while at ratios $(0.4,0.6)$ the response becomes in the increase this may due to the increase in the flame temperature gradually that cause more excitation and further emission, the flame at this ratios was hydrogen rich flame that cause cooling effect of the flame but the amount of un reacted hydrogen was high that may cause more cooling effect and cannot reach the desired flame temperature $\left(850^{\circ} \mathrm{C}\right)$ [10]. However at ratio 0.73 (standard method) and slightly above the maximum response was reached this may due to at that ratios the flame was hydrogen rich with suitable amount that produce cooled flame $\left(850^{\circ} \mathrm{C}\right)$ as discussed before in the optimization of the S-mode conditions. At these regions of FPD flames which are rich with HPO molecule and can be detected by FPD-P mode using monochromatic filter at $524 \mathrm{~nm}$.

\section{5. Suitable operating conditions for GC-FPD (P-mode)}

The suitable operating parameters as shown in Table 1 will be used for further validation of the method and also for measuring the performance of the GC/FPD P-mode for the determination of chlorpyrifos.

Table 1. The GC/FPD P mode suitable operating conditions.

\begin{tabular}{|c|c|}
\hline Parameter & Condition \\
\hline Separation Column & HP-5 (5\% crosslinked Methyl Phenyl Silicone) $25 \mathrm{~m}$ x $0.2 \mathrm{~mm}$ i.d. $\mathrm{x}$ \\
$0.52 \mu \mathrm{m}$ film thickness
\end{tabular}




\begin{tabular}{|c|c|}
\hline Oxidant gas(Air) & $110 \mathrm{ml} / \mathrm{min}$ \\
\hline Make up gas & $\mathrm{N}_{2}$ at $60 \mathrm{ml} / \mathrm{min}$ \\
\hline Mode & $\mathrm{p}$-mode \\
\hline Injection volume & $1 \mu \mathrm{L}$ \\
\hline Injection mode & splitless mode \\
\hline Injection temperature & $250{ }^{\circ} \mathrm{C}$ \\
\hline Detector temperature & $250{ }^{\circ} \mathrm{C}$ \\
\hline Temperature program & $70^{\circ} \mathrm{C}(1 \mathrm{~min})$, rate $20^{\circ} \mathrm{C} / \mathrm{min}$ to $250{ }^{\circ} \mathrm{C}$ maintained for 7 min \\
\hline
\end{tabular}

\section{6. Limit of Detection (LOD) and Limit of Quantification (LOQ)}

The limit of detection (LOD) and limit of quantification (LOQ) of FPD-P mode under the optimized condition were done to determine the lowest concentration of chlorpyrifos that could be detected by the GC-FPD-P at $(\mathrm{S} / \mathrm{N}=2)$ with applying the optimum conditions was $0.15 \mathrm{ng} / \mathrm{ml}$ as shown in Figure 6 . The limit of quantification that can be detected (at $\mathrm{S} / \mathrm{N}=10$ ) with a given accuracy and precision was $1 \mathrm{ng} / \mathrm{ml}$ with accuracy $98.5 \%$ for $(\mathrm{n}=5)$ and relative standard deviation 0.921 while the linear range was from $0.15 \mathrm{ng} / \mathrm{ml}$ to $1200 \mathrm{ppm}$.

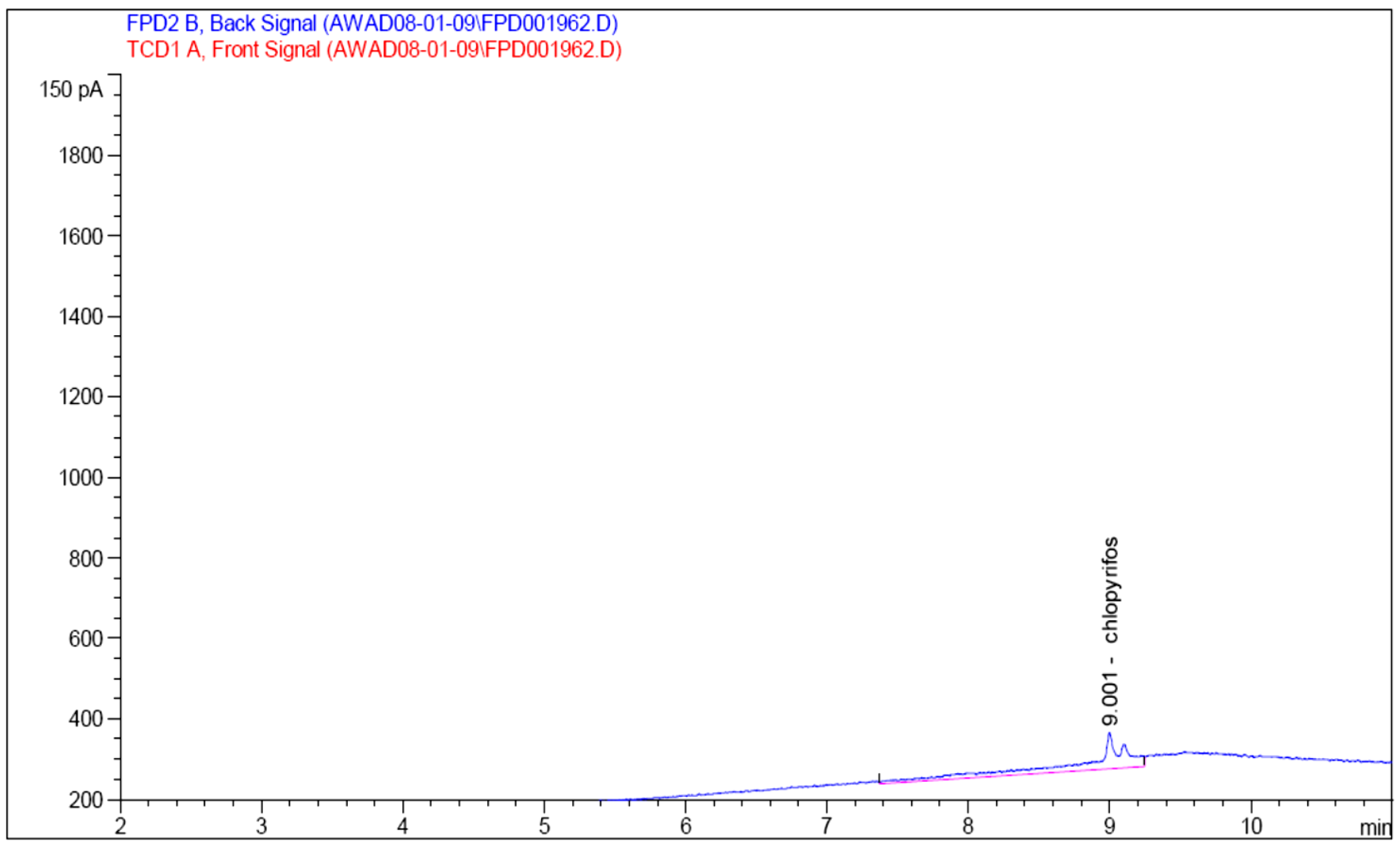

Figure 6. Chromatogram of $0.15 \mathrm{ng} / \mathrm{ml}$ chlorpyrifos LOD GC/FPD - P mode injection volume $(1 \mu 1)$, splitless, detector temperature $250^{\circ} \mathrm{C}$. 


\section{CONCLUSIONS}

Analysis of chlorpyrifos showed the validity of the optimized method used, which allowed the determination of chlorpyrifos. The method is simple, precise, rapid and reproducible, has a high level of linearity over a wide range of analyte concentrations. The factors affecting detector response are very important for a chemist to be aware specially air to hydrogen ratio and carrier gas inlet pressure.

\section{References}

[1] Lee W. J., et al., Journal of the National Cancer Institute 96(23) (2004) 1781-1789.

[2] Simon D., S. Helliwell, K. Robards, Analytica Chimica Acta 360(1) (1998) 1-16.

[3] Guardino X., et al., Journal of Chromatography A 823(1) (1998) 91-96.

[4] van der Hoff, G. R., P. van Zoonen, Journal of Chromatography A 843(1) (1999) 301-322.

[5] Lambropoulou D. A., T. A. Albanis, Journal of biochemical and biophysical methods 70(2) (1007) 195-228.

[6] Dömötörová M., E. Matisová, Journal of Chromatography A 1207(1) (2008) 1-16.

[7] Wang D., D. P. Weston, M. J. Lydy, Talanta 78(4) (2009) 1345-1351.

[8] Saeed T., et al., Food Control 12(2) (2001) 91-98.

[9] ASTM, Standard Practice for Using Flame Photometric Detectors in Gas Chromatography1, 2000.

[10] éSevécâik J., Detectors in gas chromatography. Vol. 4. 1976: Elsevier Scientific Pub. Co. (Amsterdam and New York).

[11] O. A. Zalat, M. A. Elsayed, M. S. Fayed, M. K. Abd El Megid, International Letters of Chemistry, Physics and Astronomy 2 (2014) 58-63. 